\title{
Nomograms for predicting overall survival and cancer-specific survival in patients with surgically resected intrahepatic cholangiocarcinoma
}

This article was published in the following Dove Press journal: Cancer Management and Research

\section{Kexin Ma* \\ Bing Dong* \\ Liming Wang \\ Chongyu Zhao \\ Zhaoyu Fu \\ Chi Che \\ Wuguang Liu \\ Zexuan Yang \\ Rui Liang}

Department of Hepatobiliary Surgery, The Second Hospital of Dalian Medical University, Dalian, Liaoning, People's Republic of China

*These authors contributed equally to this work
Correspondence: Liming Wang Department of Hepatobiliary Surgery, The Second Hospital of Dalian Medical University, No. 467 Zhongshan Road, Shahekou District, Dalian, Liaoning,

People's Republic of China

Tel +86 I 7709872016

Email wlm_dldr@l63.com
Purpose: To develop and validate nomograms for predicting overall survival (OS) and cancer-specific survival (CSS) in patients with surgically resected intrahepatic cholangiocarcinoma (ICC).

Patients and methods: The nomograms were developed using a development cohort of 947 ICC patients after surgery selected from Surveillance, Epidemiology, and End Results database, and externally validated using a training cohort of 159 patients admitted at our institution. Nomograms for OS and CSS were established based on the independent prognostic factors identified by COX regression models and Fine and Grey's models, respectively. The performance of the nomograms was validated internally and externally by using the concordance index (c-index), and calibration plot, and compared with that of AJCC 8th edition TNM staging system by using c-index and decision curve analysis.

Results: Age, $\mathrm{T}$ stage, $\mathrm{M}$ stage, lymph node ratio (LNR) level and tumor grade were independent prognostic predictors for OS in ICC patients, while T stage, M stage, LNR level and tumor grade were independent prognostic predictors for CSS. Nomogram predicting OS was with a c-index of 0.751 on internal validation and 0.725 up to external validation, while nomogram for CSS was with a c-index of 0.736 on internal validation and 0.718 up to external validation. Calibration plots exhibited that the nomograms-predicted and actual OS/ CSS probabilities were fitted well on both internal and external validation. Additionally, the nomograms exhibited superiority over AJCC 8th edition TNM staging system with higher c-indices and net benefit gains, in predicting OS and CSS in ICC patients after surgery.

Conclusion: The constructed nomograms could predict OS and CSS with good performance, which could be served as an effective tool for prognostic evaluation and individual treatment strategies optimization in ICC patients after surgery in clinical practice.

Keywords: intrahepatic cholangiocarcinoma, overall survival, cancer-specific survival, nomogram

\section{Introduction}

Intrahepatic cholangiocarcinoma (ICC) accounts for 5-30\% of all primary liver malignancies and ranks as the second most common liver malignancies, after hepatocellular carcinoma. ${ }^{1,2}$ Additionally, the incidence and mortality of ICC has been prominently increasing over the past three decades worldwide. ${ }^{3-5}$ The mainstay of curative treatment for ICC remains the surgical resection. In the patients with unresected ICC, the 5-year survival is dismal, ranging from $5 \%$ to $10 \%$. ${ }^{6,7}$ However, the long-term prognosis of ICC patients undergoing curative-intent surgery is still unsatisfactory, as the 5-year survival rate is $20-35 \%{ }^{8,9}$ As with other 
cancers, individual prognostic prediction for ICC patients is very important which can help the physician select the appropriate treatment for an individualized patient. Prognostic systems for individual prediction in ICC patients are still in a state of development. Traditional staging systems, such as the 8th edition American Joint Commission on Cancer (AJCC) system, are generally applicable to populations of patients, rather than a specific individual patient. Besides, AJCC system only takes tumor size, lymph node metastases, and distant metastases into account, does not consider the other associated prognostic factors, such as age, gender, tumor grade and treatment modality. Therefore, it is urgently required to develop a more accurate staging tool for individual prognostic prediction in ICC patients.

Additionally, many ICC patients aged over 60 have high rates of comorbidities and tend to suffer from competing events, ie, death from non-cancer specific diseases. ${ }^{10}$ The risk of competing events increases as the age increases. In this era of personalized cancer treatment, it is crucial to evaluate not only overall survival (OS), but also cancerspecific survival (CSS) probabilities when assessing the patients' prognosis. Prognostic nomograms have been developed and validated for use in various malignant diseases. Recent several studies ${ }^{8,11,12}$ have reported the nomograms for predicting prognosis in ICC patients, but these studies only focused on OS. To the best of our knowledge, the competing risk nomogram for ICC patients has not been ever published.

The present study was to develop nomograms for predicting OS and CSS in patients with surgically resected ICC using a cohort from the Surveillance, Epidemiology, and End Results (SEER) database and validate the performance of the nomograms internally and externally. These nomograms would provide clinicians with quantitative tools to assess patients' prognosis, for better patients' risk stratification and clinical decision making in the setting of surgically resected ICC.

\section{Materials and methods}

\section{Development cohort/SEER data}

The SEER program of the National Cancer Institute collects and publishes cancer incidence and survival data from population-based cancer registries in the United States. The study development cohort consisted of ICC patients who were diagnosed between 2004 and 2015 in the SEER program. The ICC patients who underwent curative-intent surgery were identified using International Classification of Disease for Oncology, 3rd edition (ICD-O-3), primary site code C22.1 (Intrahepatic bile duct), along with histologic/ behavior code 8160.3 (Cholangiocarcinoma).

The exclusion criteria were as follows: 1) patients with age at diagnosis were younger than 20 years old; 2) patients with other primary cancers; 3) patients with incomplete clinical characteristics; 4) patients with indefinite follow-up information; 5) patients diagnosed from a death certificate or autopsy only. The terms "Surg Prim Site" and "Reason no cancer-directed surgery" were used to identify patients who underwent surgery. Patients' clinical characteristics were collected from the SEER database, including age at diagnosis, gender, TNM stage, tumor grade, metastatic lymph nodes, total lymph nodes, follow-up information, and cause of death. AJCC 8th edition TNM staging system was used as the staging system. The AJCC 8th edition TNM stages were calculated based on tumor size, AJCC 6th or 7th edition TNM stages. ${ }^{13-15}$ The lymph node (LN) ratio (LNR) was calculated by dividing the number of metastatic LNs to the total number of LN examined. LNR value was converted into a categorical variable based on its optimal cutoff value determined by receiver operating characteristic curve. SEER data were extracted using SEER*Stat 8.3.5 (National Cancer Institute, Bethesda, MD, USA) software.

OS was defined as the time from the date of diagnosis to the death due to any cause or the last follow-up. CSS was defined as the time from the date of diagnosis to the death attributable to ICC. Recurrence-free survival (RFS) was defined as the interval from the date of surgery to the date of last follow-up for non-recurrent patients.

\section{External validation cohort}

The study validation cohort comprised 159 ICC patients who underwent curative-intent surgery between December 2004 and December 2017 at the Department of Hepatobiliary Surgery, the Second Hospital of Dalian Medical University. The inclusion and exclusion criteria of the validation cohort were same to those of the development cohort. Patients' clinical characteristics were collected from the electronic medical records.

\section{Ethical approval}

All the procedures performed in studies involving human participants were in accordance with the ethical standards of the institutional and/or national research committee and with the 1964 Helsinki Declaration and its later 
amendments or comparable ethical standards. The study has been approved by the ethics committee of the Second Hospital of Dalian Medical University (No.1509-39). All authors have signed authorization and received permission from SEER to access and use the dataset. Informed consent was waived due to the retrospective nature of this study, but all data were kept confidential.

\section{Statistical analysis}

Continuous variables were compared by Student's $t$-test or Mann-Whitney $U$ test depending on their distributions, while categorical variables were compared by Chi-square test. Distributions of continuous variables were tested by Kolmogorov-Smirnov. Kaplan-Meier curves were constructed to estimate the OS and log-rank tests were used to assess the statistical differences. Univariate and multivariate COX proportional hazards analyses were used to determine the independent prognostic predictors for OS. HR and the associated 95\% CI were estimated. Subsequently, the clinical significant predictors were used to develop a nomogram for 1-, 3-and 5-year OS in patients with ICC by using rms package in R software.

CSS and non-CSS were considered as two competing events. The cumulative incidence function (CIF) curves were used to illustrate the CSS and statistical differences were carried out using the Gray test. Univariate and multivariate Fine and Gray proportional hazards models were used to identify significant factors associated with CSS. Subdistribution HRwith associated 95\% CI was reported. Afterward, we used the significant factors to construct a nomogram for 1-, 3- and 5-year CSS in patients with ICC.

Nomogram validation consisted of two activities: internal validation and external validation. Firstly, internal validation was performed via a bootstrap method with 1000 resamples. The discrimination ability of the nomogram was evaluated by using the concordance index (c-index). The marginal estimate versus model was used to derive calibration plots which reflect the agreement between nomogram-predicted and the actual survival probabilities. Secondly, external validation was performed in the validation cohort. The nomograms were used to assess each patient in the validation cohort. And then c-indices and calibration plots were generated to evaluate the discriminative performance and predictive accuracy of the nomograms. Furthermore, we compared the performance of the nomograms with AJCC 8th edition TNM staging system by using the c-index and decision curve analysis. Decision curve analysis was employed to examine the clinical net benefit of a predictive model by using rmda package in $\mathrm{R}$ software.

All statistical analyses were analyzed using SPSS 22.0 software (SPSS, Inc., Chicago, IL, USA) and R software version 3.5.2 (http://www.r-project.org) with $\mathrm{R}$ packages cmprsk, rmda, rms, and survival packages. A two-tailed $P$ value $<0.05$ was considered statistically significant.

\section{Results}

\section{Patient and tumor characteristics}

After applying the inclusion and exclusion criteria, the development cohort consisted of ICC 947 patients from SEER Database, and validation cohort included 159 ICC patients from our hospital. Flowchart of the study participants selected is depicted in Figure 1. The clinical and tumor characteristics are summarized in Table 1. The median age at diagnosis was 64 years old (range: $21-89$ years old) in the development cohort and 67 years old (range: $35-88$ years old) in the validation cohort. In both cohorts, most patients were classified as moderate grade, in T1-T2 Stage, without regional LN or distant metastasis.

\section{OS and CSS in the study cohort}

The median follow-up period was 19 months (range: 1142 months) for the development cohort and 21 months (range: 2-140 months) for validation cohort. In the development cohort, the OS rates at 1-, 3- and 5-year were $80.7 \%, 46.3 \%$ and $32.7 \%$, respectively, and the CSS rates at 1-, 3- and 5-year were $88.7 \%, 67.0 \%$ and $59.0 \%$, respectively. In the validation cohort, the OS rates at 1-, 3and 5 -year were $75.7 \%, 42.3 \%$ and $36.8 \%$, respectively, the CSS rates at 1-, 3- and 5-year were $86.7 \%, 60.2 \%$ and $53.7 \%$, respectively and the RFS rates at 1-, 3- and 5-year were $61.5 \%, 38.6 \%$ and $30.5 \%$, respectively. Table 2 summarizes the 1-, 3- and 5-year OS, and CSS stratified by the factors examined. Non-CSS rates were summarized in the Table S1.

Kaplan-Meier curves revealed that cumulative OS rates were statistically decreased in patients who were male (Figure S1A), with older ages (Figure S1B), advanced T stage (Figure S1C), N stage (Figure S1D), M stage (Figure S1E), higher LNR level (Figure S1F), poorer grade (Figure S1G) or larger tumor size (Figure S1H). CIF curves showed that the cumulative CSS rates were significantly lower in patients with advanced $\mathrm{T}$ stage (Figure S2A), N stage (Figure S2B), M stage (Figure S2C), poorer 


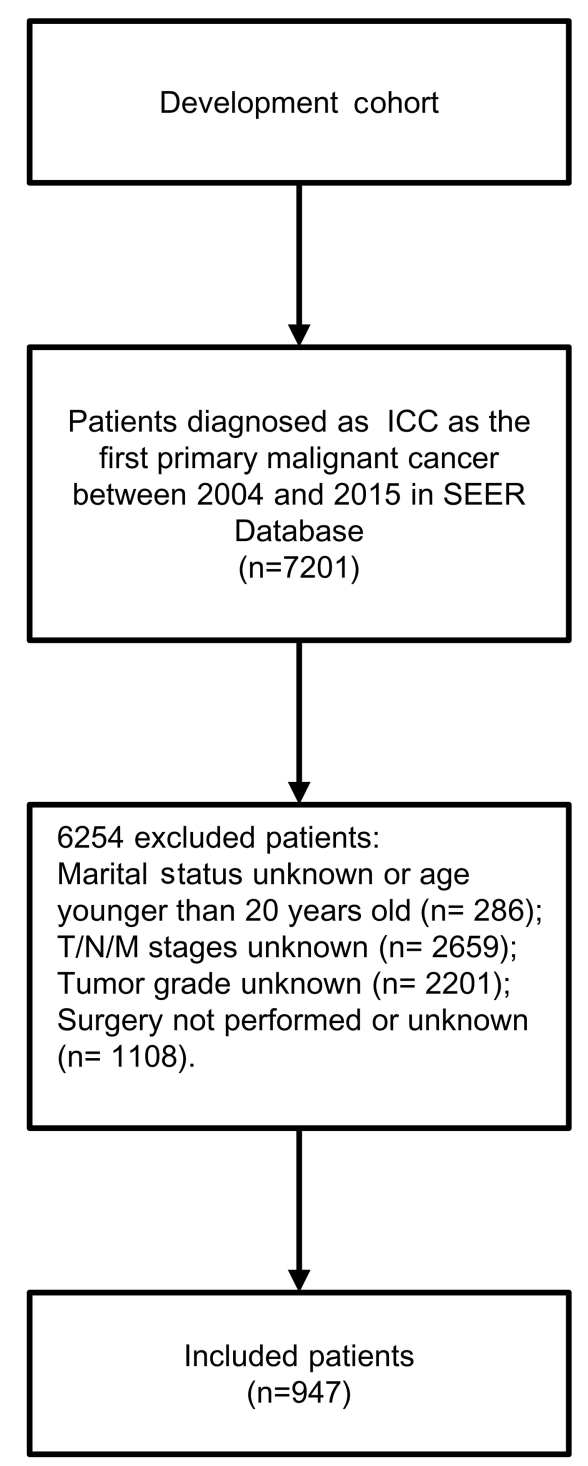

Figure I The flowchart of the study cohort.

grade (Figure S2D), higher LNR (Figure S2E) or larger tumor size (Figure S2F). Besides, male patients (Figure S3A) or patients aged over 75 years old (Figure S3B) had poorer non-CSS.

\section{Independent prognostic factors for OS and CSS}

In univariate $\mathrm{COX}$ analysis, age, gender, $\mathrm{T}$ stage, $\mathrm{N}$ stage, $M$ stage, LNR level, grade and tumor size were significantly associated with OS in ICC patients. After adjusting for covariates, age, T stage, M stage, LNR level and tumor grade were retained as the independent prognostic predictors in the multivariate COX regression (Table 3). Univariate competing risk analysis demonstrated that

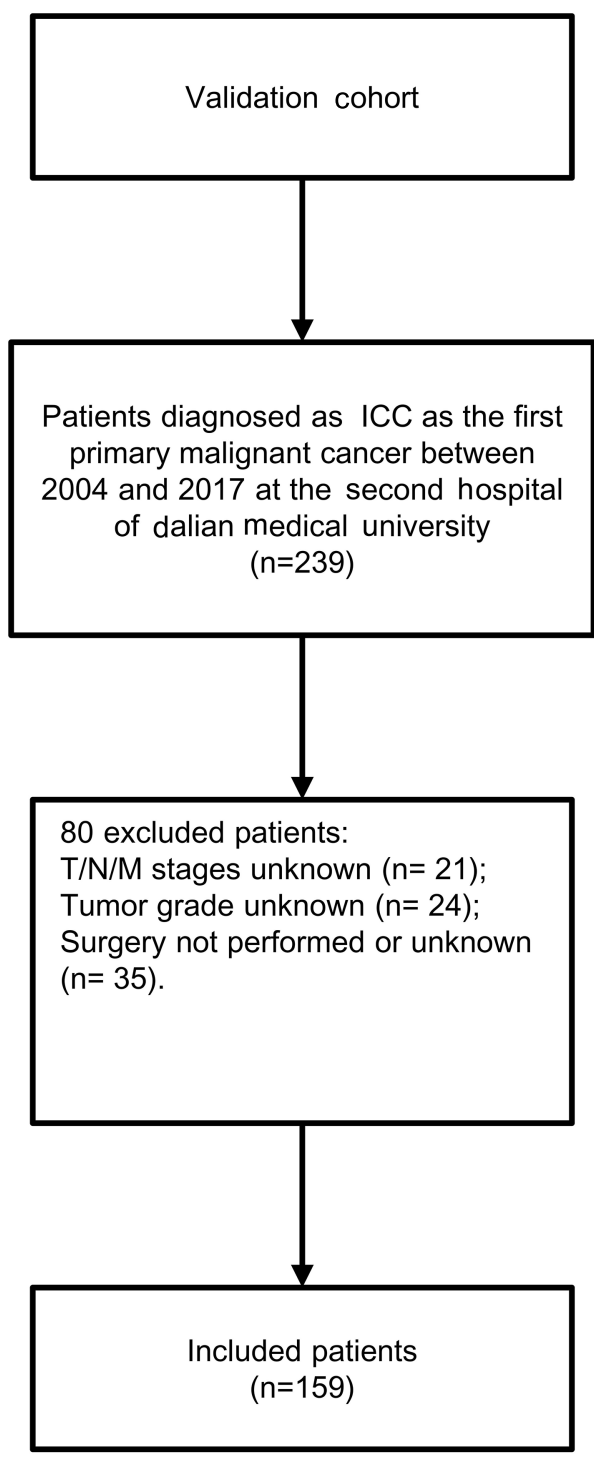

T stage, $\mathrm{N}$ stage, $\mathrm{M}$ stage, LNR level, tumor grade and tumor size had a prominent effect on CSS in ICC patients. These factors were included into the multivariate competing risk analysis. In multivariate competing risk analysis, T stage, M stage, LNR level and tumor grade were independently predictive of CSS in ICC patients (Table 4).

\section{Nomograms construction and validation}

All the independent prognostic predictors for OS and CSS were integrated into the nomogram for predicting 1-, 3and 5-year OS (Figure 2A) and CSS (Figure 2B), respectively. When subjected to the internal validation, the nomograms showed excellent accuracy with c-indices of $0.751(0.680-0.822)$ for OS, and $0.736(0.658-0.814)$ for 
Table I Clinical characteristics of patients in the development cohort and training cohort

\begin{tabular}{|c|c|c|c|}
\hline Variables & $\begin{array}{l}\text { SEER cohort } \\
(n=947)\end{array}$ & $\begin{array}{l}\text { Validation } \\
\text { cohort }(n=\mid 59)\end{array}$ & $P$-value \\
\hline $\begin{array}{l}\text { Gender } \\
\text { Male } \\
\text { Female }\end{array}$ & $\begin{array}{l}446(47.10) \\
501(52.90)\end{array}$ & $\begin{array}{l}85(53.46) \\
74(46.54)\end{array}$ & 0.137 \\
\hline $\begin{array}{l}\text { Age (years) } \\
\quad<55 \\
55-74 \\
\geq 75\end{array}$ & $\begin{array}{l}215(22.70) \\
569(60.08) \\
163(17.21)\end{array}$ & $\begin{array}{l}35(22.01) \\
107(67.3) \\
17(10.69)\end{array}$ & 0.149 \\
\hline $\begin{array}{l}\text { Marriage } \\
\text { Married } \\
\text { Unmarried }\end{array}$ & $\begin{array}{l}603(63.67) \\
344(36.33)\end{array}$ & $\begin{array}{l}112(70.44) \\
47(29.56)\end{array}$ & 0.099 \\
\hline $\begin{array}{l}\text { T stage } \\
\text { Tla } \\
\text { TIb } \\
\text { T2 } \\
\text { T3 } \\
\text { T4 }\end{array}$ & $\begin{array}{l}226(23.86) \\
162(17.11) \\
247(26.08) \\
184(19.43) \\
128(13.52)\end{array}$ & $\begin{array}{l}35(22.01) \\
25(15.72) \\
40(25.16) \\
26(16.35) \\
33(20.75)\end{array}$ & 0.113 \\
\hline $\begin{array}{l}\mathrm{N} \text { stage } \\
\text { No } \\
\text { NI }\end{array}$ & $\begin{array}{l}753(79.5 \mathrm{I}) \\
194(20.49)\end{array}$ & $\begin{array}{l}135(84.91) \\
24(15.09)\end{array}$ & 0.114 \\
\hline $\begin{array}{l}\text { M stage } \\
\text { Mo } \\
\text { MI }\end{array}$ & $\begin{array}{l}873(92.19) \\
74(7.81)\end{array}$ & $\begin{array}{l}142(89.31) \\
17(10.69)\end{array}$ & 0.222 \\
\hline $\begin{array}{l}\text { LNR } \\
\quad<0.17 \\
\geq 0.17\end{array}$ & $\begin{array}{l}781(82.47) \\
166(17.53)\end{array}$ & $\begin{array}{l}122(76.73) \\
37(23.27)\end{array}$ & 0.084 \\
\hline $\begin{array}{l}\text { Grade } \\
\text { Well } \\
\text { Moderate } \\
\text { Poor }\end{array}$ & $\begin{array}{l}115(12.14) \\
517(54.59) \\
315(33.26)\end{array}$ & $\begin{array}{l}23(14.47) \\
88(55.35) \\
48(30.19)\end{array}$ & 0.191 \\
\hline $\begin{array}{l}\text { Tumor size }(\mathrm{cm}) \\
\quad<3.5 \\
3.5-5.4 \\
5.5-7.4 \\
\geq 7.5\end{array}$ & $\begin{array}{l}237(25.03) \\
244(25.77) \\
202(21.33) \\
264(27.88)\end{array}$ & $\begin{array}{l}32(20.13) \\
40(25.16) \\
48(30.19) \\
39(24.53)\end{array}$ & \\
\hline
\end{tabular}

Abbreviations: LNR, lymph node ratio.

CSS (Table 5). In the external validation, the nomograms also exhibited good accuracy with c-indices of 0.725 (0.666-0.784) for OS, and $0.718(0.669-0.767)$ for CSS (Table 5). Both internal and external calibration plots for 1-, 3- and 5-year OS (Figures 3 and 4) and 1-, 3- and 5year CSS (Figures 5 and 6) demonstrated fair agreement between nomogram-predicted probabilities and actual probabilities.

\section{Comparisons of the performance of the} nomograms and AJCC 8th edition TNM

\section{staging system}

The discriminative performance of the nomograms and AJCC 8th edition TNM staging system for OS and CSS is summarized in Table 5 by analyzing the c-indices. The nomograms had significantly higher c-indices than AJCC 8th edition TNM staging system in both the development cohort and validation cohort $(P<0.001)$. In the decision curve analyses, the nomograms for predicting 1-,3- and 5-year OS and CSS demonstrated higher net benefit gains in a wide range of threshold probabilities compared with the AJCC 8th edition TNM staging system (Figures 7 and 8$)$.

\section{Discussion}

The present study developed nomograms for predicting OS and CSS in patients with surgically resected ICC, using the data derived from the SEER database, and validated internally and externally. The external validation was performed using an independent cohort collected in our hospital. These nomograms showed favorable discrimination and calibration which would aid in patient counseling and clinical decision-making.

ICC is the second most common histologic type of liver malignant tumor. ${ }^{16}$ The incidence and mortality of ICC are steadily on the rise worldwide. Accurate and efficient information on prognosis is important for both clinicians and patients to make an individualized treatment decision. Traditional staging systems, such as AJCC TNM staging system, include limited ICC-related variables and subject to evaluating the prognosis for a specific patient. Recent report based on a large population study revealed that the AJCC 8th edition TNM staging system had the moderate discriminative power in predicting OS in ICC patients. ${ }^{17}$ Nomograms are statistical tools that allow simultaneous consideration of multiple factors to help visually provide the probability of a specific outcome for an individual patient. ${ }^{18}$ Moreover, there were numerous advantages observed for the utility of the nomograms in cancer prognostic prediction, including user-friendliness, individualized assessment and comprehensibility. Several previous studies have proposed the prognostic nomograms in ICC patients, while which only focused on the OS. To the best of our knowledge, the present study is the first study to develop and validate the prognostic nomograms for both OS and CSS in ICC patients. 
Table 2 Cumulative OS and CSS in patients with surgically resected ICC

\begin{tabular}{|c|c|c|c|c|c|c|c|c|}
\hline \multirow[t]{2}{*}{ Variable } & \multicolumn{4}{|c|}{ Cumulative OS } & \multicolumn{4}{|c|}{ Cumulative CSS } \\
\hline & I-year & 3-year & 5 -year & $P$-value & I-year & 3-year & 5-year & $P$-value \\
\hline Total & 0.807 & 0.463 & 0.327 & & 0.886 & 0.670 & 0.590 & \\
\hline $\begin{array}{c}\text { Gender } \\
\text { Female } \\
\text { Male }\end{array}$ & $\begin{array}{l}0.829 \\
0.782\end{array}$ & $\begin{array}{l}0.497 \\
0.425\end{array}$ & $\begin{array}{l}0.355 \\
0.293\end{array}$ & 0.030 & $\begin{array}{l}0.890 \\
0.873\end{array}$ & $\begin{array}{l}0.657 \\
0.688\end{array}$ & $\begin{array}{l}0.568 \\
0.611\end{array}$ & 0.304 \\
\hline $\begin{array}{l}\text { Age (years) } \\
\quad<55 \\
\quad 55-74 \\
\geq 75\end{array}$ & $\begin{array}{l}0.855 \\
0.818 \\
0.707\end{array}$ & $\begin{array}{l}0.467 \\
0.497 \\
0.347\end{array}$ & $\begin{array}{l}0.338 \\
0.342 \\
0.255\end{array}$ & 0.013 & $\begin{array}{l}0.892 \\
0.86 I \\
0.804\end{array}$ & $\begin{array}{l}0.581 \\
0.644 \\
0.575\end{array}$ & $\begin{array}{l}0.480 \\
0.537 \\
0.494\end{array}$ & \\
\hline $\begin{array}{l}\text { Marriage } \\
\text { Married } \\
\text { Unmarried }\end{array}$ & $\begin{array}{l}0.824 \\
0.779\end{array}$ & $\begin{array}{l}0.478 \\
0.439\end{array}$ & $\begin{array}{l}0.323 \\
0.332\end{array}$ & 0.237 & $\begin{array}{l}0.867 \\
0.908\end{array}$ & $\begin{array}{l}0.672 \\
0.67\end{array}$ & $\begin{array}{l}0.604 \\
0.566\end{array}$ & 0.907 \\
\hline $\begin{array}{l}\text { T stage } \\
\text { Tla } \\
\text { Tlb } \\
\text { T2 } \\
\text { T3 } \\
\text { T4 }\end{array}$ & $\begin{array}{l}0.888 \\
0.853 \\
0.815 \\
0.773 \\
0.639\end{array}$ & $\begin{array}{l}0.657 \\
0.615 \\
0.459 \\
0.267 \\
0.216\end{array}$ & $\begin{array}{l}0.496 \\
0.464 \\
0.329 \\
0.100 \\
0.216\end{array}$ & $<0.001$ & $\begin{array}{l}0.919 \\
0.922 \\
0.847 \\
0.767 \\
0.806\end{array}$ & $\begin{array}{l}0.803 \\
0.741 \\
0.631 \\
0.458 \\
0.352\end{array}$ & $\begin{array}{l}0.691 \\
0.618 \\
0.542 \\
0.345 \\
0.300\end{array}$ & $<0.001$ \\
\hline $\begin{array}{l}\mathrm{N} \text { stage } \\
\text { No } \\
\mathrm{NI}\end{array}$ & $\begin{array}{l}0.84 \\
0.674\end{array}$ & $\begin{array}{l}0.521 \\
0.228\end{array}$ & $\begin{array}{l}0.388 \\
0.077\end{array}$ & $<0.001$ & $\begin{array}{l}0.904 \\
0.795\end{array}$ & $\begin{array}{l}0.729 \\
0.430\end{array}$ & $\begin{array}{l}0.654 \\
0.310\end{array}$ & $<0.001$ \\
\hline $\begin{array}{l}\text { M stage } \\
\text { Mo } \\
\text { MI }\end{array}$ & $\begin{array}{l}0.829 \\
0.55\end{array}$ & $\begin{array}{l}0.486 \\
0.199\end{array}$ & $\begin{array}{l}0.345 \\
0.112\end{array}$ & $<0.001$ & $\begin{array}{l}0.872 \\
0.689\end{array}$ & $\begin{array}{l}0.636 \\
0.393\end{array}$ & $\begin{array}{l}0.535 \\
0.304\end{array}$ & $<0.001$ \\
\hline $\begin{array}{l}\text { LNR } \\
\qquad \begin{array}{l}<0.17 \\
\geq 0.17\end{array}\end{array}$ & $\begin{array}{l}0.844 \\
0.628\end{array}$ & $\begin{array}{l}0.523 \\
0.175\end{array}$ & $\begin{array}{l}0.381 \\
0.075\end{array}$ & $<0.001$ & $\begin{array}{l}0.887 \\
0.719\end{array}$ & $\begin{array}{l}0.678 \\
0.318\end{array}$ & $\begin{array}{l}0.578 \\
0.229\end{array}$ & $<0.001$ \\
\hline $\begin{array}{l}\text { Grade } \\
\text { Well } \\
\text { Moderate } \\
\text { Poor }\end{array}$ & $\begin{array}{l}0.874 \\
0.84 I \\
0.724\end{array}$ & $\begin{array}{l}0.623 \\
0.506 \\
0.329\end{array}$ & $\begin{array}{l}0.486 \\
0.348 \\
0.231\end{array}$ & $<0.001$ & $\begin{array}{l}0.911 \\
0.89 \\
0.783\end{array}$ & $\begin{array}{l}0.745 \\
0.662 \\
0.486\end{array}$ & $\begin{array}{l}0.672 \\
0.546 \\
0.405\end{array}$ & $<0.001$ \\
\hline $\begin{array}{l}\text { Tumor size }(\mathrm{cm}) \\
\quad \leq 3.5 \\
3.5-5.4 \\
5.5-7.4 \\
\geq 7.5\end{array}$ & $\begin{array}{l}0.833 \\
0.834 \\
0.802 \\
0.763\end{array}$ & $\begin{array}{l}0.483 \\
0.535 \\
0.449 \\
0.389\end{array}$ & $\begin{array}{l}0.376 \\
0.383 \\
0.311 \\
0.249\end{array}$ & 0.003 & $\begin{array}{l}0.899 \\
0.903 \\
0.898 \\
0.849\end{array}$ & $\begin{array}{l}0.742 \\
0.763 \\
0.632 \\
0.554\end{array}$ & $\begin{array}{l}0.667 \\
0.684 \\
0.562 \\
0.461\end{array}$ & $<0.001$ \\
\hline
\end{tabular}

Abbreviations: ICC, intrahepatic cholangiocarcinoma; OS, overall survival; CSS, cancer-specific survival; LNR, lymph node ratio.

Nomograms construction began with the identification of independent predictive factors for OS and CSS in ICC patients after surgery. For the nomogram predicting OS, we used univariate and multivariate $\mathrm{COX}$ proportional hazards regression model to determine the independent prognostic factors for OS. Multivariate COX regression analysis revealed that age, $\mathrm{T}$ stage, $\mathrm{M}$ stage, LNR and tumor grade were independent prognostic predictors for OS in patients with ICC. In the presence of competing risk, univariate and multivariate Fine and Gray's subdistribution hazard regression model, is more appropriate, as it can take into account the informative nature of censoring and estimate the proportion of CSS more accurately. ${ }^{19-22}$ Therefore, for the development of nomogram for 
Table 3 Univariate and multivariate COX regression analyzes for OS in patients with surgically resected ICC

\begin{tabular}{|c|c|c|c|c|c|c|}
\hline \multirow[t]{2}{*}{ Variables } & \multicolumn{3}{|c|}{ Univariate COX analysis } & \multicolumn{3}{|c|}{ Multivariate COX analysis } \\
\hline & HR & $95 \% \mathrm{Cl}$ & $P$-value & HR & $95 \% \mathrm{Cl}$ & $P$-value \\
\hline \multicolumn{7}{|l|}{ Gender } \\
\hline Female & Ref & & & Ref & & \\
\hline Male & 1.226 & $1.020-1.473$ & 0.030 & 1.099 & $0.702-1.181$ & 0.478 \\
\hline \multicolumn{7}{|l|}{ Age (years) } \\
\hline$<55$ & Ref & & & Ref & & \\
\hline $55-74$ & 1.000 & $0.799-1.250$ & 0.997 & 1.294 & $1.021-1.640$ & 0.033 \\
\hline$\geq 75$ & 1.415 & $1.069-1.872$ & 0.015 & $\mathrm{I} .883$ & $1.40 \mathrm{I}-2.532$ & $<0.001$ \\
\hline \multicolumn{7}{|l|}{ Marriage } \\
\hline Married & Ref & & & & & \\
\hline Unmarried & 0.893 & $0.739-1.078$ & 0.237 & & & \\
\hline \multicolumn{7}{|l|}{ T stage } \\
\hline $\mathrm{Tla}$ & Ref & & & Ref & & \\
\hline TIb & 1.130 & $0.815-1.566$ & 0.464 & 1.148 & $0.768-1.716$ & 0.501 \\
\hline $\mathrm{T} 2$ & 1.694 & $1.275-2.250$ & $<0.001$ & 1.396 & $1.027-1.898$ & 0.033 \\
\hline $\mathrm{T} 3$ & 2.786 & $2.096-3.700$ & $<0.001$ & 2.177 & $1.530-3.096$ & $<0.001$ \\
\hline $\mathrm{T} 4$ & 3.127 & $2.272-4.303$ & $<0.001$ & 2.456 & $1.702-3.542$ & $<0.001$ \\
\hline \multicolumn{7}{|l|}{$N$ stage } \\
\hline No & Ref & & & Ref & & \\
\hline NI & 2.436 & $1.975-3.004$ & $<0.001$ & 1.330 & $0.927-1.908$ & 0.121 \\
\hline \multicolumn{7}{|l|}{$M$ stage } \\
\hline MO & Ref & & & Ref & & \\
\hline $\mathrm{MI}$ & 2.405 & $1.795-3.223$ & $<0.001$ & 1.745 & $1.25 \mathrm{I}-2.434$ & 0.001 \\
\hline \multicolumn{7}{|l|}{ LNR } \\
\hline$<0.17$ & Ref & & & Ref & & \\
\hline$\geq 0.17$ & 2.798 & $2.255-3.47$ I & $<0.001$ & 1.692 & $|| 49-2.49 \mid$. & 0.008 \\
\hline \multicolumn{7}{|l|}{ Grade } \\
\hline Well & Ref & & & Ref & & \\
\hline Moderate & 1.498 & $1.076-2.086$ & 0.017 & 1.277 & $0.913-1.786$ & 0.153 \\
\hline Poor & 2.315 & $\mid .643-3.26 \mathrm{I}$ & $<0.001$ & 1.764 & $1.237-2.516$ & 0.002 \\
\hline \multicolumn{7}{|l|}{ Tumor size $(\mathrm{cm})$} \\
\hline$<3.5$ & Ref & & & Ref & & \\
\hline $3.5-5.4$ & 1.196 & $0.650-1.075$ & 0.162 & 1.009 & $0.752-1.354$ & 0.952 \\
\hline $5.5-7.4$ & 1.455 & $1.124-1.882$ & 0.004 & 1.092 & $0.602-3.514$ & 0.405 \\
\hline$\geq 7.5$ & 1.512 & $1.180-1.937$ & 0.001 & 1.099 & $0.626-3.652$ & 0.359 \\
\hline
\end{tabular}

Abbreviations: ICC, intrahepatic cholangiocarcinoma; OS, overall survival; LNR, lymph node ratio.

predicting CSS in ICC patients, we employed Fine and Gray's competing risk regression analysis to screen the independent risk factors for CSS. Multivariate competing risk regression analysis demonstrated that $\mathrm{T}$ stage, $\mathrm{M}$ stage, LNR and tumor grade were independent prognostic predictors for CSS in patients with ICC.

ICC is rare in patients younger than 40 years old, and shows peak incidence between the ages of 50 and 70 years. ${ }^{23}$ Patients with advancing age are at a high risk of concurrent comorbidities, which have a direct impact on the non-CSS. ${ }^{24}$ In the present study, elder patients showed significantly lower OS and non-CSS. Multivariate analyses revealed that advancing age was an independent prognostic factor for OS, but not for CSS. This finding strongly indicated that non-cancer specific mortality was an important competing event in elder patients, which was consistent with previous studies. $^{25,26}$ 
Table 4 Univariate and multivariate competing risk analyzes for CSS in patients with surgically resected ICC

\begin{tabular}{|c|c|c|c|c|c|c|}
\hline \multirow[t]{2}{*}{ Variables } & \multicolumn{3}{|c|}{ Univariate competing risk analysis } & \multicolumn{3}{|c|}{ Multivariate competing risk analysis } \\
\hline & SHR & $95 \% \mathrm{Cl}$ & $P$-value & SHR & $95 \% \mathrm{Cl}$ & $P$-value \\
\hline \multicolumn{7}{|l|}{ Gender } \\
\hline Female & Ref & & & & & \\
\hline Male & 1.074 & $0.937-1.231$ & 0.306 & & & \\
\hline \multicolumn{7}{|l|}{ Age (years) } \\
\hline$<55$ & Ref & & & & & \\
\hline $55-74$ & 1.075 & $0.946-1.221$ & 0.268 & & & \\
\hline$\geq 75$ & 1.054 & $0.983-1.13$ & 0.137 & & & \\
\hline \multicolumn{7}{|l|}{ Marriage } \\
\hline Married & Ref & & & & & \\
\hline Unmarried & 0.985 & $0.776-1.250$ & 0.900 & & & \\
\hline \multicolumn{7}{|l|}{ T stage } \\
\hline $\mathrm{Tla}$ & Ref & & & Ref & & \\
\hline TIb & 1.251 & $1.042-1.502$ & 0.016 & 1.514 & $0.9|3-2.51|$ & 0.108 \\
\hline $\mathrm{T} 2$ & 1.384 & I.098-1.744 & 0.006 & 1.690 & $|.078-2.65|$ & 0.022 \\
\hline T3 & 1.696 & $1.263-2.277$ & $<0.001$ & 3.414 & $1.936-6.021$ & $<0.001$ \\
\hline $\mathrm{T} 4$ & 2.635 & $1.620-4.287$ & $<0.001$ & 3.762 & $2.105-6.724$ & $<0.001$ \\
\hline \multicolumn{7}{|l|}{$\mathrm{N}$ stage } \\
\hline No & Ref & & & Ref & & \\
\hline $\mathrm{NI}$ & 1.802 & $1.43 \mid-2.270$ & $<0.001$ & 1.384 & $0.906-2.115$ & 0.133 \\
\hline \multicolumn{7}{|l|}{ M stage } \\
\hline MO & Ref & & & Ref & & \\
\hline MI & 1.692 & $1.299-2.204$ & $<0.001$ & 1.296 & I.138-1.475 & $<0.001$ \\
\hline \multicolumn{7}{|l|}{ LNR } \\
\hline$<0.17$ & Ref & & & & & \\
\hline$\geq 0.17$ & 2.065 & $|.435-2.97|$ & $<0.001$ & 2.664 & $2.043-3.475$ & $<0.001$ \\
\hline \multicolumn{7}{|l|}{ Grade } \\
\hline Well & Ref & & & Ref & & \\
\hline Moderate & 1.931 & $1.394-2.675$ & $<0.001$ & 1.432 & I.134-1.807 & 0.003 \\
\hline Poor & 3.08 & $|.644-5.77|$ & $<0.001$ & 2.134 & $1.532-2.972$ & $<0.001$ \\
\hline \multicolumn{7}{|l|}{ Tumor size $(\mathrm{cm})$} \\
\hline$\leq 3.5$ & Ref & & & Ref & & \\
\hline $3.5-5.4$ & 1.992 & $1.332-2.979$ & 0.001 & I. 127 & $0.839-1.515$ & 0.427 \\
\hline $5.5-7.4$ & 1.931 & $1.394-2.675$ & $<0.001$ & 1.331 & $0.944-1.876$ & 0.103 \\
\hline$\geq 7.5$ & 3.08 & $|.644-5.77|$ & $<0.001$ & 1.335 & $0.925-1.926$ & 0.122 \\
\hline
\end{tabular}

Abbreviations: ICC, intrahepatic cholangiocarcinoma; CSS, cancer-specific survival; LNR, lymph node ratio.

Many reports have confirmed that tumor-related factors including tumor size, tumor invasiveness, metastatic status and lymph nodes status were to some extent associated with the prognosis in patients with ICC. ${ }^{14,17,27}$ AJCC TNM staging system is developed based on these elements, in which $\mathrm{T}$ stage reflects tumor size and invasiveness, $\mathrm{M}$ stage reflects metastatic status and $\mathrm{N}$ stage represents the LN metastasis. The present study also demonstrated that patients with advanced $\mathrm{T}$ stage, $\mathrm{M}$ stage and $\mathrm{N}$ stage had poor OS and CSS of ICC. Furthermore, multivariate analyses revealed that $\mathrm{T}$ stage and $\mathrm{M}$ stage were independent risk factors for both OS and CSS in ICC patients. With regards to LN status, many studies have shown the negative role of metastatic lymph nodes in the prognosis of various tumors. ${ }^{28,29} \mathrm{LNR}$, as a novel parameter, incorporates not only the number of metastatic lymph nodes, but also the total number of nodes examined by the pathologist, which enables 


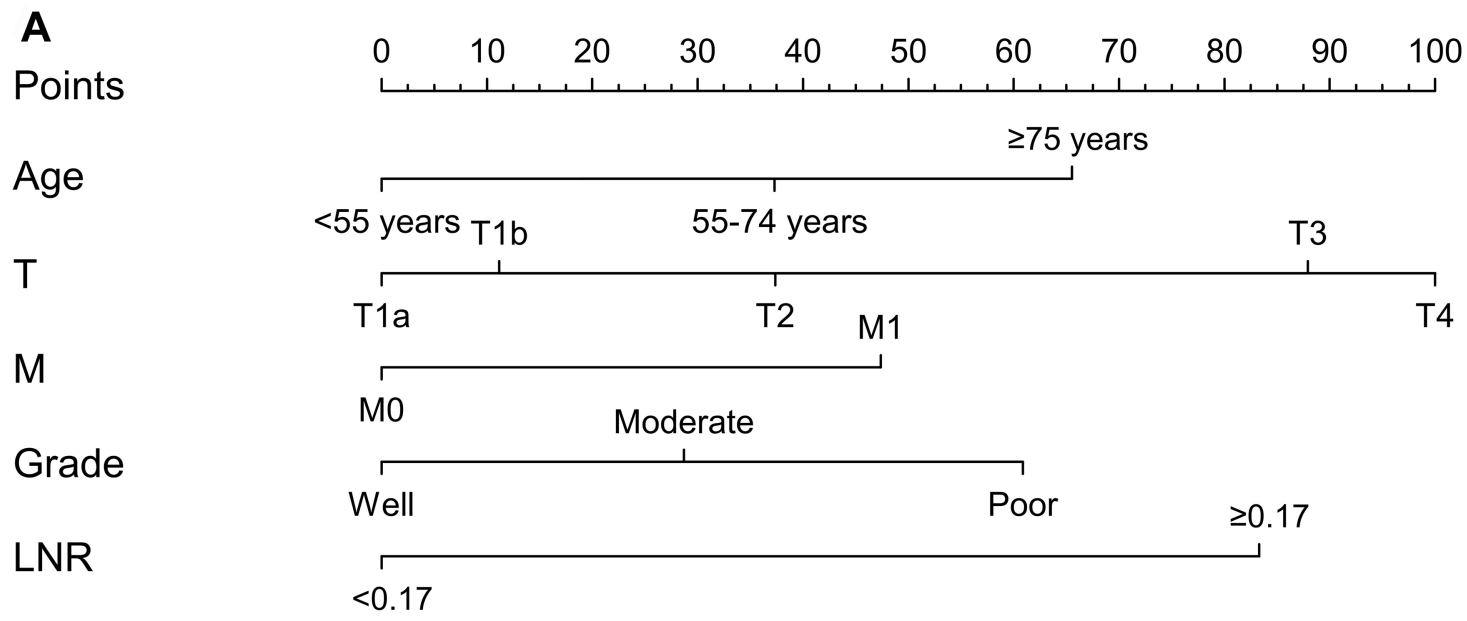

Total points

1-year OS prob.

\begin{tabular}{|c|c|c|c|c|c|c|c|c|}
\hline 0 & 50 & 100 & 150 & 200 & 250 & 300 & 350 & 400 \\
\hline & 0 . & & 0.8 & 0.7 & $0.6 \quad 0.5$ & 0.4 & $0.3 \quad 0.2$ & \\
\hline
\end{tabular}

3-year OS prob.

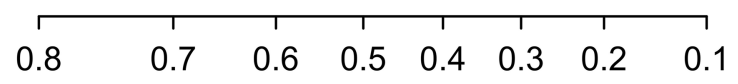

5-year OS prob.

$\begin{array}{lllllll}0.7 & 0.6 & 0.5 & 0.4 & 0.3 & 0.2 & 0.1\end{array}$

B

Points

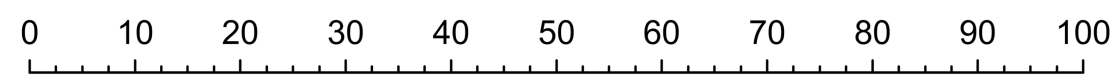

$\mathrm{T}$

M

$\mathrm{T} 1 \mathrm{~b}$

T3

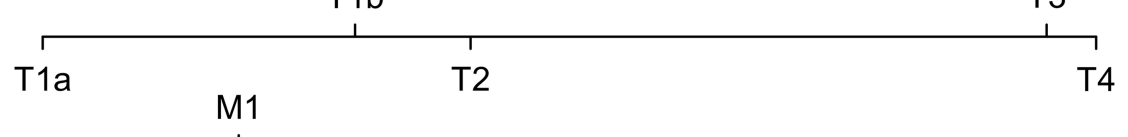

LNR

Grade

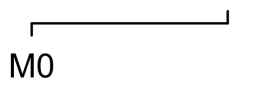

$\geq 0.17$

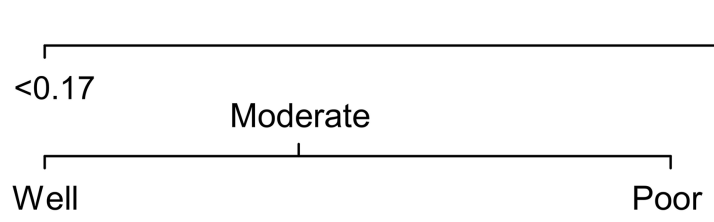

Total points

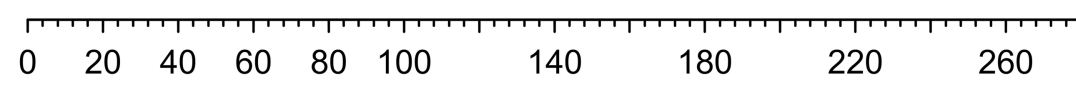

1-year CSS prob.

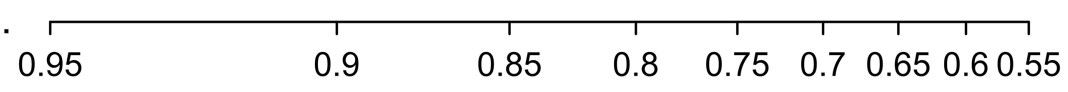

3-year CSS prob.

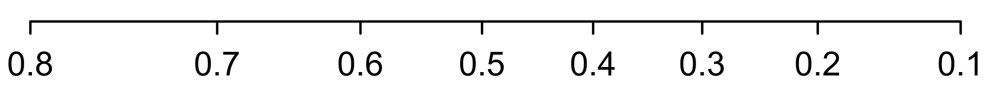

5-year CSS prob.

\begin{tabular}{lllllll}
\hline 0.7 & 0.6 & 0.5 & 0.4 & 0.3 & 0.2 & 0.1
\end{tabular}

Figure 2 Nomograms predicting I-, 3-and 5-year OS (A) and CSS (B) in patients with ICC after surgery. Each subtype within these variables was assigned a score on the point scale. By summing up the total score and locating it on the total point scale, we could draw a vertical line down to get the nomogram-predicted probability at each time point. Abbreviations: CSS, cancer-specific survival; ICC, intrahepatic cholangiocarcinoma; LNR, lymph node ratio; OS, overall survival. 
Table 5 Comparisons of c-indices between the nomograms and AJCC 8th edition TNM staging system in patients with surgically resected ICC

\begin{tabular}{|l|l|l|l|}
\hline & $\begin{array}{l}\text { Nomogram } \\
\mathbf{( 9 5 \% ~ C l )}\end{array}$ & AJCC 8th edition TNM staging system (95\% CI) & $P$-value \\
\hline Training cohort, OS & $0.751(0.680-0.822)$ & $0.658(0.607-0.709)$ & $<0.001$ \\
Training cohort, CSS & $0.736(0.658-0.814)$ & $0.661(0.592-0.730)$ & $<0.001$ \\
Validation cohort, OS & $0.725(0.666-0.784)$ & $0.632(0.567-0.697)$ & $<0.001$ \\
Validation cohort, CSS & $0.718(0.669-0.767)$ & $0.621(0.572-0.670)$ & $<0.001$ \\
\hline
\end{tabular}

Abbreviation: ICC, intrahepatic cholangiocarcinoma.

information on extent of disease, comprehensiveness of surgical resection, and thoroughness of pathological evaluation to be condensed into one parameter. ${ }^{30-32}$ Tamandl et $\mathrm{al}^{33}$ reported that LNR was a good prognostic factor for survival in ICC patients after curative surgery. Our present study also demonstrated the prognostic role of elevated LNR for both OS and CSS in ICC patients. What is more, our finding indicated that LNR could outperform the AJCC N stage in prognosis prediction in ICC patients, which was consistent with the previous studies. ${ }^{34-36}$

It is well accepted that tumor differentiation can explain some of the heterogeneity associated with the expected course and clinical outcome in patients with various tumors. ${ }^{37,38}$ Tumor grade is a measure of the degree of differentiation of the tumor. In the present study, tumor grade was also observed as an independent prognostic predictor for both OS and CSS in ICC patients, which was similar to the previous researches. Furthermore, our study showed that the predictive value of tumor differentiation was independent of T stage, M stage and LNR, so that our nomograms for OS and CSS also incorporated tumor grade. According to the constructed nomograms, patients with different tumor grade would probably have different nomogram points and different OS and CSS probabilities even if they have the same TNM stages. This finding could partially explain that our nomograms showed superior performance to the AJCC 8th TNM staging system in predicting OS and CSS in ICC patients.

In this era of personalized cancer therapy, it is important to consider both OS and CSS, at the time of decision making. As far as we know, it is the first study to build nomograms for predicting OS and CSS in patients with ICC after surgery. Our nomograms, incorporating easily accessible factors in clinical practice, enabled easy calculation of individualized OS and CSS probabilities for patients with ICC after surgery. Moreover, the nomograms displayed relatively high accuracy with overall c-indices more than 0.70 and well-fitted calibration curves in both the development cohort and validation cohort. Besides, high predictive accuracy does not necessarily indicate whether such predictive model has high clinical usefulness. ${ }^{39,40}$ Decision curve analysis, recommended by previous studies on the prognostic predictive models, can evaluate the clinical practical value of a predictive model by quantifying its net benefit according to the threshold probability. ${ }^{41-43}$ Therefore, we introduced the decision curve analysis to examine the usefulness of our nomograms in clinical practice. The decision curve analyses not only confirmed the clinical validity of our nomograms for OS and CSS, but also proved that our nomograms had better clinical usefulness compared with AJCC 8th edition TNM staging system, in ICC patients after surgery.

However, our study has some limitations. Firstly, some variables relevant with ICC prognosis, for example, vascular invasion, morphologic pattern, hepatitis status and serum tumor marker, were not studied, as they were unavailable in SEER database. These variables will be included in our future research. Secondly, as with the other retrospective studies, both development and validation cohorts subjected to selection bias. Thirdly, the SEER database lacked the information in terms of RFS. Finally, although our nomograms for OS and CSS in ICC patients were externally validated with satisfactory performance, the external validation cohort just consisted of patients from a single institution in Asia. Additional studies with multi-institutional cohorts will be warranted to validate the accuracy of the nomograms. However, notwithstanding these limitations, our present study pioneered the use of nomograms incorporating clinically feasible variables for predicting OS and CSS in ICC patients, which were of clinical significance in the assessment of ICC patients' prognosis.

\section{Conclusion}

In summary, we developed nomograms predicting 1-, 3and 5-year OS and CSS in patients with ICC after surgery, 

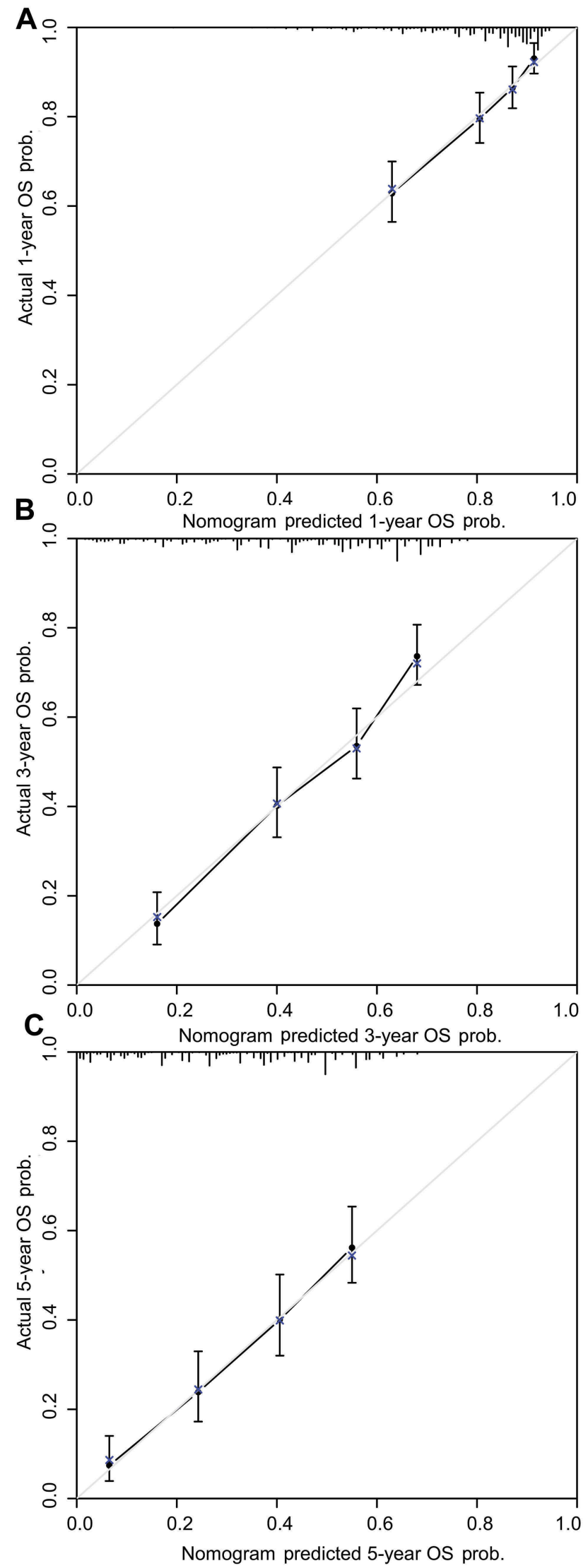

Figure 3 Calibration curves of the nomogram predicting OS in the development cohort: (A) I-year OS; (B) 3-year OS; (C) 5-year OS. OS: overall survival. 

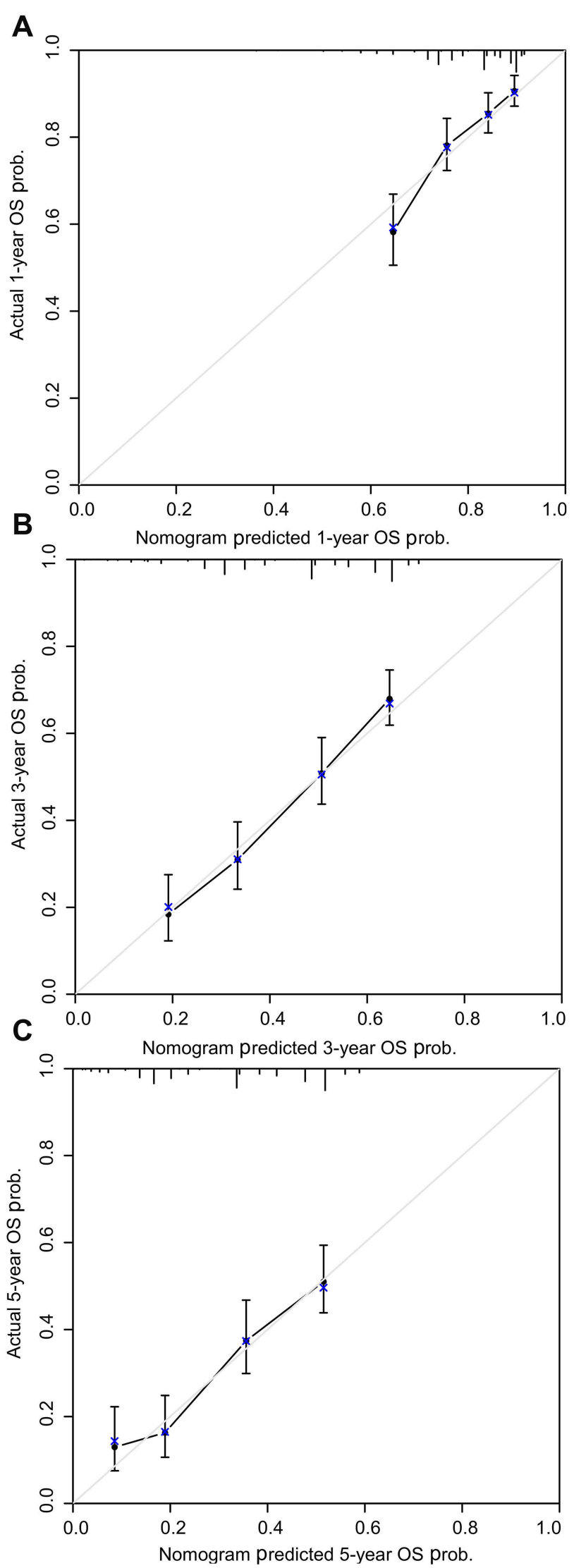

Figure 4 Calibration curves of the nomogram predicting OS in the training cohort: (A) I-year OS; (B) 3-year OS; (C) 5-year OS. Abbreviation: OS, overall survival. 

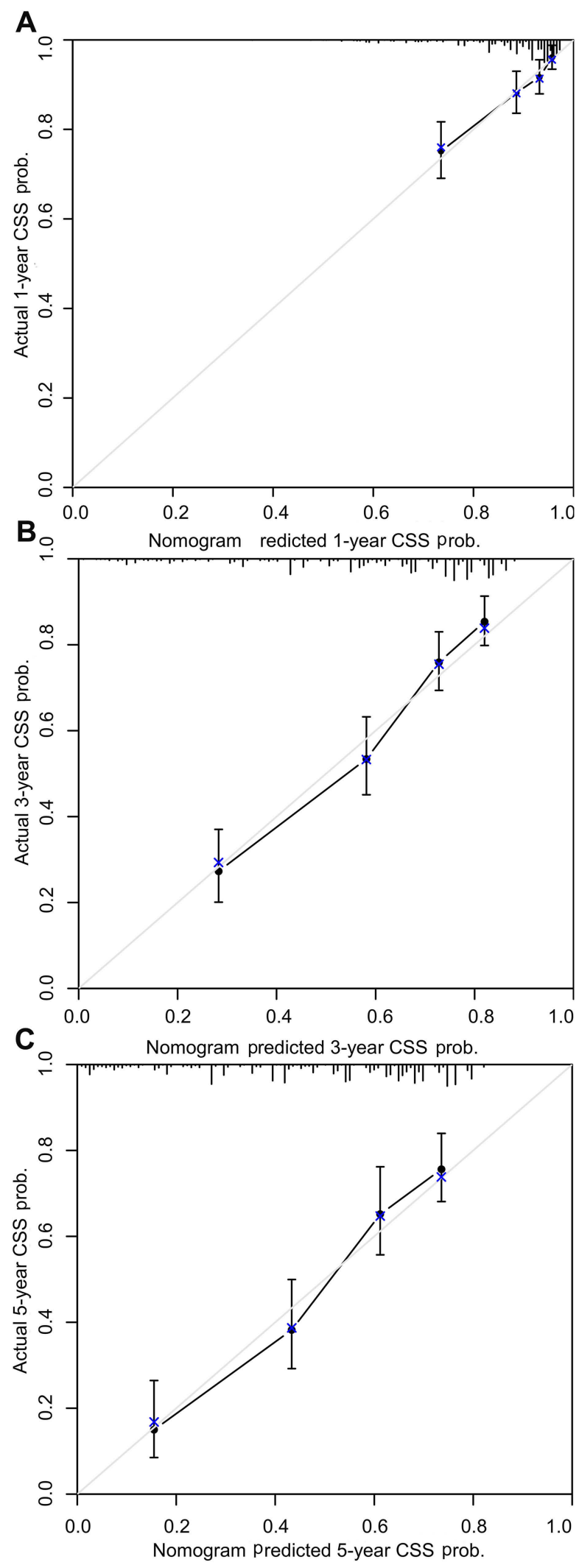

Figure 5 Calibration curves of the nomogram predicting CSS in the development cohort: (A) I-year CSS; (B) 3-year CSS; (C) 5-year CSS. Abbreviation: CSS, cancer-specific survival. 

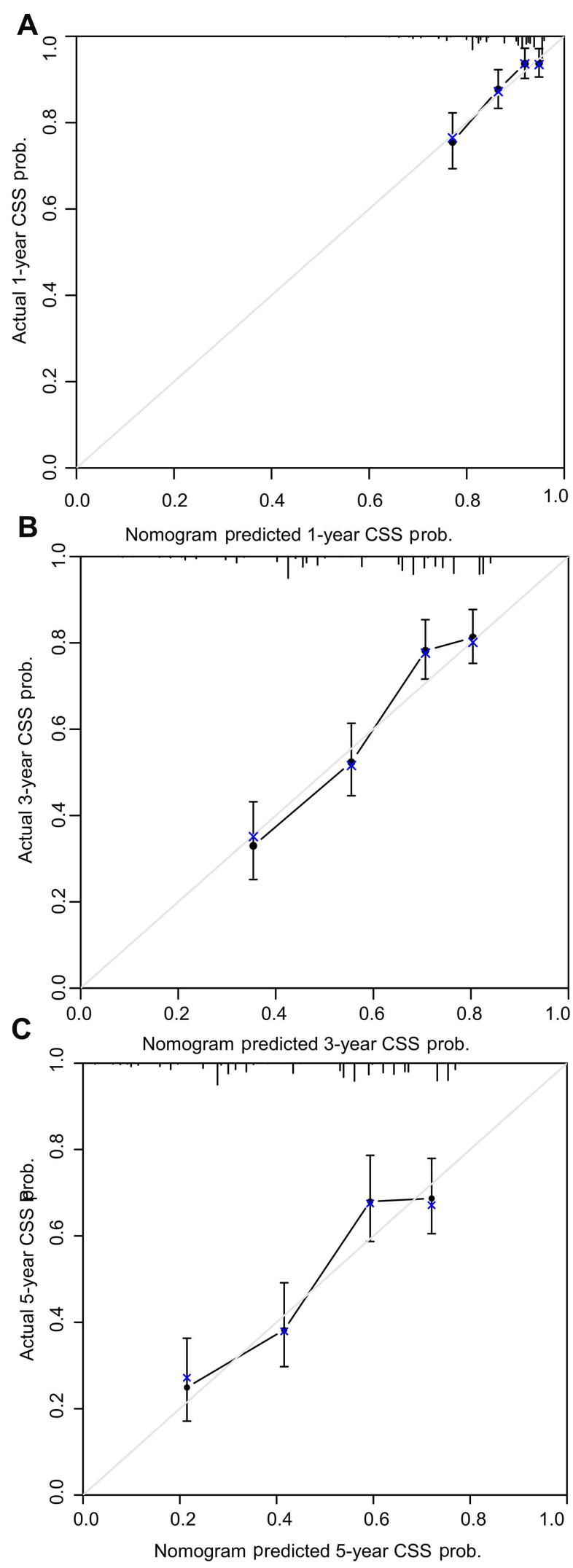

Figure 6 Calibration curves of the nomogram predicting CSS in the training cohort: (A) I-year CSS; (B) 3-year CSS; (C) 5-year CSS. Abbreviation: CSS, cancer-specific survival. 

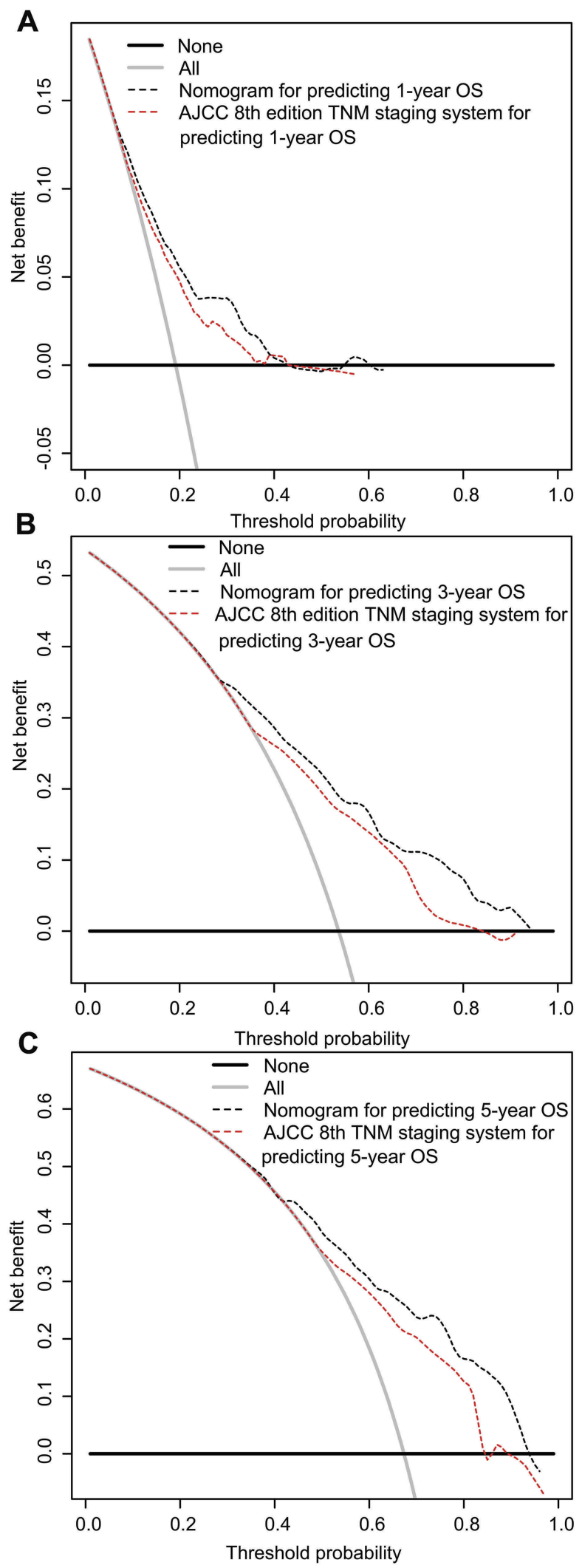

Figure 7 Decision curve analysis of nomograms and AJCC 8th edition staging system for predicting (A) I-year OS; (B) 3-year OS; (C) 5-year OS. The grey line indicates the assumption that all patients die. The black line indicates that the assumption that all patients survive.

Abbreviation: OS, overall survival. 

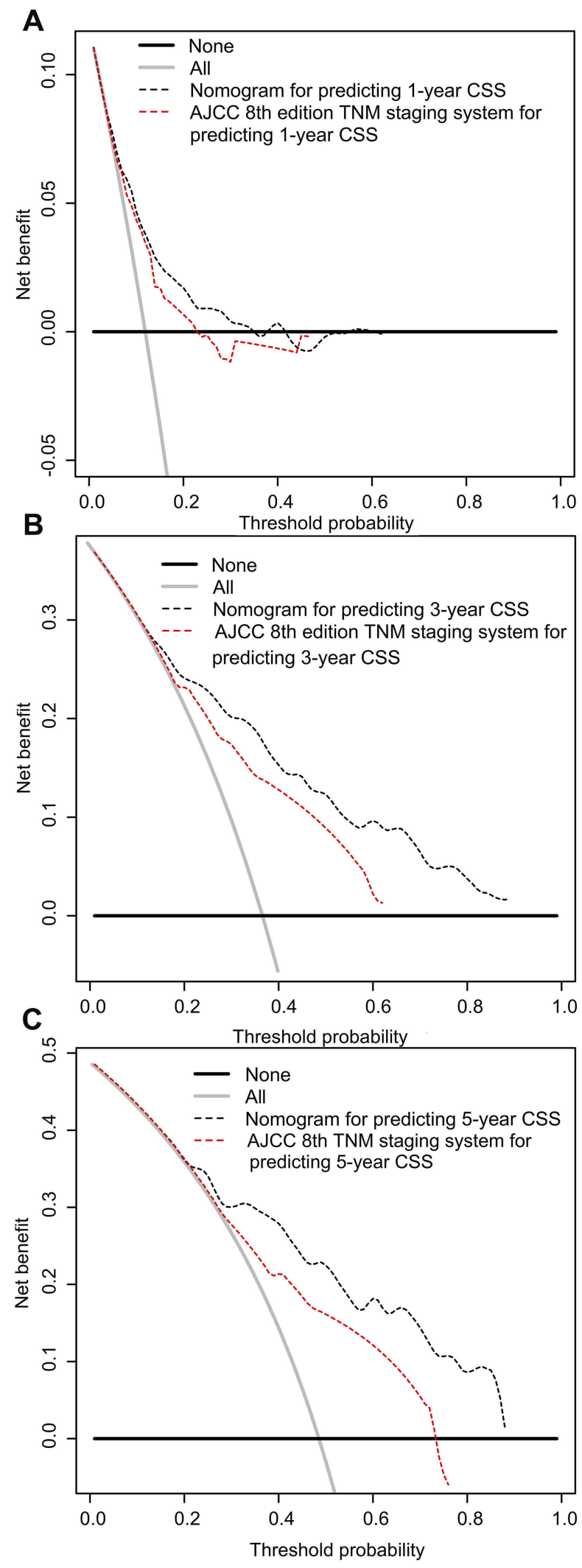

Figure 8 Decision curve analysis of nomograms and AJCC 8th edition staging system for predicting (A) I-year CSS; (B) 3-year CSS; (C) 5-year CSS. The grey line indicates the assumption that all patients die. The black line indicates that the assumption that all patients survive.

Abbreviation: CSS: cancer-specific survival. 
based on a large population-based cohort. The present nomograms integrating easily accessible factors demonstrated good accuracy and discrimination as shown by internal and external validation, which would consider as practical and easy-to-use tools to aid in risk-stratification and clinical decision making in ICC patients.

\section{Author contributions}

LW, KM and BD made a major contribution to the conception and design of the study, and prepared the first draft of the manuscript. KM and BD contributed to the data acquisition and performed the statistical analyses. CZ, ZF, CC, WL, ZY and RL revised the manuscript. All authors contributed to data analysis, drafting or revising the article, gave final approval of the version to be published, and agree to be accountable for all aspects of the work.

\section{Disclosure}

The authors report no conflicts of interest in this work.

\section{References}

1. Liver Cancer Study Group of J. Primary liver cancer in Japan. Clinicopathologic features and results of surgical treatment. Ann Surg. 1990;211(3):277-287.

2. Pawlik TM. Biliary tract and primary liver tumors. Surg Oncol Clin N Am. 2014;23(2):xv-xvi. doi:10.1016/j.soc.2013.11.005

3. Malhi H, Gores GJ. Cholangiocarcinoma: modern advances in understanding a deadly old disease. J Hepatol. 2006;45(6):856-867. doi:10.1016/j.jhep.2006.09.001

4. Welzel TM, McGlynn KA, Hsing AW, O’Brien TR, Pfeiffer RM. Impact of classification of hilar cholangiocarcinomas (Klatskin tumors) on the incidence of intra- and extrahepatic cholangiocarcinoma in the United States. $J$ Natl Cancer Inst. 2006;98(12):873-875. doi:10.1093/jnci/djj234

5. Endo I, Gonen M, Yopp AC, et al. Intrahepatic cholangiocarcinoma: rising frequency, improved survival, and determinants of outcome after resection. Ann Surg. 2008;248(1):84-96. doi:10.1097/ SLA.0b013e318176c4d3

6. Shaib Y, El-Serag HB. The epidemiology of cholangiocarcinoma. Semin Liver Dis. 2004;24(2):115-125. doi:10.1055/s-2004-828889

7. Mavros MN, Economopoulos KP, Alexiou VG, Pawlik TM. Treatment and prognosis for patients with intrahepatic cholangiocarcinoma: systematic review and meta-analysis. JAMA Surg. 2014;149 (6):565-574. doi:10.1001/jamasurg.2013.5137

8. Wang Y, Li J, Xia Y, et al. Prognostic nomogram for intrahepatic cholangiocarcinoma after partial hepatectomy. J Clin Oncol. 2013;31 (9):1188-1195. doi:10.1200/JCO.2012.41.5984

9. de Jong MC, Nathan H, Sotiropoulos GC, et al. Intrahepatic cholangiocarcinoma: an international multi-institutional analysis of prognostic factors and lymph node assessment. J Clin Oncol. 2011;29 (23):3140-3145. doi:10.1200/JCO.2011.35.6519

10. Antwi SO, Mousa OY, Patel T. Racial, ethnic, and age disparities in incidence and survival of intrahepatic cholangiocarcinoma in the United States; 1995-2014. Ann Hepatol. 2018;17(2):274-285. doi:10.5604/01.3001.0010.8659
11. Wang M, Gao Y, Feng H, et al. A nomogram incorporating six easily obtained parameters to discriminate intrahepatic cholangiocarcinoma and hepatocellular carcinoma. Cancer Med. 2018;7(3):646-654. doi:10.1002/cam4.1341

12. Yeh CN, Wang SY, Chen YY, et al. A prognostic nomogram for overall survival of patients after hepatectomy for intrahepatic cholangiocarcinoma. Anticancer Res. 2016;36(8):4249-4258.

13. Amin MB, Greene FL, Edge SB, et al. The Eighth Edition AJCC cancer staging manual: continuing to build a bridge from a population-based to a more "personalized" approach to cancer staging. CA Cancer J Clin. 2017;67(2):93-99. doi:10.3322/ caac. 21388

14. Kamarajah SK. Evaluation of the AJCC 8th edition staging system for pathologically versus clinically staged intrahepatic cholangiocarcinoma (icca): a time to revisit a dogma? A Surveillance, Epidemiology, and End Results (SEER) Analysis. $J$ Gastrointest Cancer. 2018. doi:10.1007/s12029-018-0084-5

15. Lee AJ, Chun YS. Intrahepatic cholangiocarcinoma: the AJCC/ UICC 8th edition updates. Chin Clin Oncol. 2018;7(5):52. doi: $10.21037 / \mathrm{cco}$

16. Chinchilla-Lopez P, Aguilar-Olivos NE, Garcia-Gomez J, et al. Prevalence, risk factors, and survival of patients with intrahepatic cholangiocarcinoma. Ann Hepatol. 2017;16(4):565-568. doi:10.5604/ 01.3001.0010.0293

17. Kim Y, Moris DP, Zhang XF, et al. Evaluation of the 8th edition American Joint Commission on Cancer (AJCC) staging system for patients with intrahepatic cholangiocarcinoma: a surveillance, epidemiology, and end results (SEER) analysis. J Surg Oncol. 2017;116 (6):643-650. doi:10.1002/jso.24720

18. Kattan MW. Nomograms. Introduction. Semin Urol Oncol. 2002;20 (2):79-81.

19. Pintilie M. Analysing and interpreting competing risk data. Stat Med. 2007;26(6):1360-1367. doi:10.1002/sim.2655

20. Zhang Z, Geskus RB, Kattan MW, Zhang H, Liu T. Nomogram for survival analysis in the presence of competing risks. Ann Transl Med. 2017;5(20):403. doi:10.21037/atm.2017.07.27

21. Carmona R, Zakeri K, Green G, et al. Improved method to stratify elderly patients with cancer at risk for competing events. J Clin Oncol. 2016;34(11):1270-1277. doi:10.1200/ JCO.2015.65.0739

22. Lau B, Cole SR, Gange SJ. Competing risk regression models for epidemiologic data. Am J Epidemiol. 2009;170(2):244-256. doi:10.1093/aje/kwp107

23. Gupta A, Dixon E. Epidemiology and risk factors: intrahepatic cholangiocarcinoma. Hepatobiliary Surg Nutr. 2017;6(2):101-104. doi:10.21037/hbsn.2017.01.02

24. McGlynn KA, Tarone RE, El-Serag HB. A comparison of trends in the incidence of hepatocellular carcinoma and intrahepatic cholangiocarcinoma in the United States. Cancer Epidemiol Biomarkers Prev. 2006;15(6):1198-1203. doi:10.1158/10559965.EPI-05-0811

25. Eggener SE, Scardino PT, Walsh PC, et al. Predicting 15-year prostate cancer specific mortality after radical prostatectomy. $J$ Urol. 2011;185(3):869-875. doi:10.1016/j.juro.2010.10.057

26. Eguchi T, Bains S, Lee MC, et al. Impact of increasing age on causespecific mortality and morbidity in patients with stage I Non-smallcell lung cancer: a competing risks analysis. J Clin Oncol. 2017;35 (3):281-290. doi:10.1200/JCO.2016.69.0834

27. Farges O, Fuks D, Le Treut YP, et al. AJCC 7th edition of TNM staging accurately discriminates outcomes of patients with resectable intrahepatic cholangiocarcinoma: by the AFC-IHCC-2009 study group. Cancer. 2011;117(10):2170-2177. doi:10.1002/cncr.25712

28. Zhang CH, Li YY, Zhang QW, et al. The prognostic impact of the metastatic lymph nodes ratio in colorectal cancer. Front Oncol. 2018;8:628. doi:10.3389/fonc.2018.00628 
29. Ou SH, Zell JA, Ziogas A, Anton-Culver H. Prognostic factors for survival of stage I nonsmall cell lung cancer patients: a populationbased analysis of 19,702 stage I patients in the California Cancer Registry from 1989 to 2003. Cancer. 2007;110(7):1532-1541. doi:10.1002/cncr.22938

30. Schneider DF, Chen H, Sippel RS. Impact of lymph node ratio on survival in papillary thyroid cancer. Ann Surg Oncol. 2013;20 (6):1906-1911. doi:10.1245/s10434-012-2802-8

31. Wen YS, Xi KX, Xi KX, et al. The number of resected lymph nodes is associated with the long-term survival outcome in patients with T2 N0 non-small cell lung cancer. Cancer Manag Res. 2018;10:68696877. doi:10.2147/CMAR.S186047

32. Nwogu CE, Groman A, Fahey D, et al. Number of lymph nodes and metastatic lymph node ratio are associated with survival in lung cancer. Ann Thorac Surg. 2012;93(5):1614-1619; discussion 16191620. doi:10.1016/j.athoracsur.2012.01.065

33. Tamandl D, Kaczirek K, Gruenberger B, et al. Lymph node ratio after curative surgery for intrahepatic cholangiocarcinoma. $\mathrm{Br} J$ Surg. 2009;96(8):919-925. doi:10.1002/bjs.6654

34. Wang J, Dang P, Raut CP, et al. Comparison of a lymph node ratiobased staging system with the 7th AJCC system for gastric cancer: analysis of 18,043 patients from the SEER database. Ann Surg. 2012;255(3):478-485. doi:10.1097/SLA.0b013e31824857e2

35. Lee YC, Yang PJ, Zhong Y, Clancy TE, Lin MT, Wang J. Lymph node ratio-based staging system outperforms the Seventh AJCC System for Gastric Cancer: validation Analysis With National Taiwan University Hospital Cancer Registry. Am J Clin Oncol. 2017;40(1):35-41. doi:10.1097/COC.0000000000000110
36. Zhang J, Lv L, Ye Y, Jiang K, Shen Z, Wang S. Comparison of metastatic lymph node ratio staging system with the 7 th AJCC system for colorectal cancer. J Cancer Res Clin Oncol. 2013;139 (11):1947-1953. doi:10.1007/s00432-013-1525-y

37. Greene FL, Sobin LH. The staging of cancer: a retrospective and prospective appraisal. CA Cancer J Clin. 2008;58(3):180-190. doi:10.3322/CA.2008.0001

38. Rochefort MM, Ankeny JS, Kadera BE, et al. Impact of tumor grade on pancreatic cancer prognosis: validation of a novel TNMG staging system. Ann Surg Oncol. 2013;20(13):4322-4329. doi:10.1245/s10434-0133159-3

39. Vickers AJ, Elkin EB. Decision curve analysis: a novel method for evaluating prediction models. Med Decis Making. 2006;26(6):565574. doi:10.1177/0272989X06295361

40. Balachandran VP, Gonen M, Smith JJ, DeMatteo RP. Nomograms in oncology: more than meets the eye. Lancet Oncol. 2015;16(4):e173e180. doi:10.1016/S1470-2045(14)71116-7

41. Wang ZX, Qiu MZ, Jiang YM, Zhou ZW, Li GX, Xu RH. Comparison of prognostic nomograms based on different nodal staging systems in patients with resected gastric cancer. J Cancer. 2017;8(6):950-958. doi:10.7150/jca.17370

42. Hijazi Z, Oldgren J, Lindback J, et al. The novel biomarker-based ABC (age, biomarkers, clinical history)-bleeding risk score for patients with atrial fibrillation: a derivation and validation study. Lancet. 2016;387 (10035):2302-2311. doi:10.1016/S0140-6736(16)00741-8

43. Dong F, Shen Y, Gao F, et al. Nomograms to predict individual prognosis of patients with primary small cell carcinoma of the bladder. J Cancer. 2018;9(7):1152-1164. doi:10.7150/jca.23344 


\section{Supplementary materials}

Table SI Cumulative non-CSS in patients with surgically resected ICC

\begin{tabular}{|c|c|c|c|c|}
\hline \multirow[t]{2}{*}{ Variable } & \multicolumn{4}{|c|}{ Non-CSS } \\
\hline & I-year & 3-year & 5 -year & $P$-value \\
\hline Total & 0.921 & 0.793 & 0.737 & \\
\hline Gender & & & & 0.004 \\
\hline Female & 0.930 & 0.838 & 0.788 & \\
\hline Male & 0.896 & 0.731 & 0.673 & \\
\hline Age (years) & & & & 0.019 \\
\hline$<55$ & 0.963 & 0.885 & 0.858 & \\
\hline $55-74$ & 0.957 & 0.853 & 0.805 & \\
\hline$\geq 75$ & 0.903 & 0.772 & 0.761 & \\
\hline Marriage & & & & 0.302 \\
\hline Married & 0.914 & 0.791 & 0.732 & \\
\hline Unmarried & 0.915 & 0.785 & 0.740 & \\
\hline $\mathrm{T}$ stage & & & & 0.817 \\
\hline $\mathrm{Tla}$ & 0.969 & 0.854 & 0.804 & \\
\hline Tlb & 0.931 & 0.873 & 0.845 & \\
\hline $\mathrm{T} 2$ & 0.968 & 0.828 & 0.787 & \\
\hline T3 & 0.913 & 0.86 & 0.815 & \\
\hline $\mathrm{T} 4$ & 0.944 & 0.836 & 0.823 & \\
\hline$N$ stage & & & & 0.797 \\
\hline No & 0.923 & 0.786 & 0.729 & \\
\hline $\mathrm{NI}$ & 0.877 & 0.801 & 0.762 & \\
\hline$M$ stage & & & & 0.445 \\
\hline Mo & 0.957 & $0.85 I$ & 0.811 & \\
\hline MI & 0.861 & 0.807 & 0.807 & \\
\hline LNR & & & & 0.479 \\
\hline LNR $<0.17$ & 0.958 & 0.845 & 0.803 & \\
\hline$L N R \geq 0.17$ & 0.909 & 0.856 & 0.846 & \\
\hline Grade & & & & 0.681 \\
\hline I & 0.962 & 0.878 & 0.814 & \\
\hline II & 0.951 & 0.843 & 0.806 & \\
\hline III+IV & 0.949 & 0.845 & 0.827 & \\
\hline Tumor size $(\mathrm{cm})$ & & & & 0.305 \\
\hline$\leq 3.5$ & 0.965 & 0.742 & 0.709 & \\
\hline $3.5-5.4$ & 0.931 & 0.742 & 0.709 & \\
\hline $5.5-7.4$ & 0.904 & 0.816 & 0.749 & \\
\hline$\geq 7.5$ & 0.914 & 0.834 & 0.789 & \\
\hline
\end{tabular}

Abbreviations: ICC, intrahepatic cholangiocarcinoma; CSS, cancer-specific survival; LNR, lymph node ratio. 

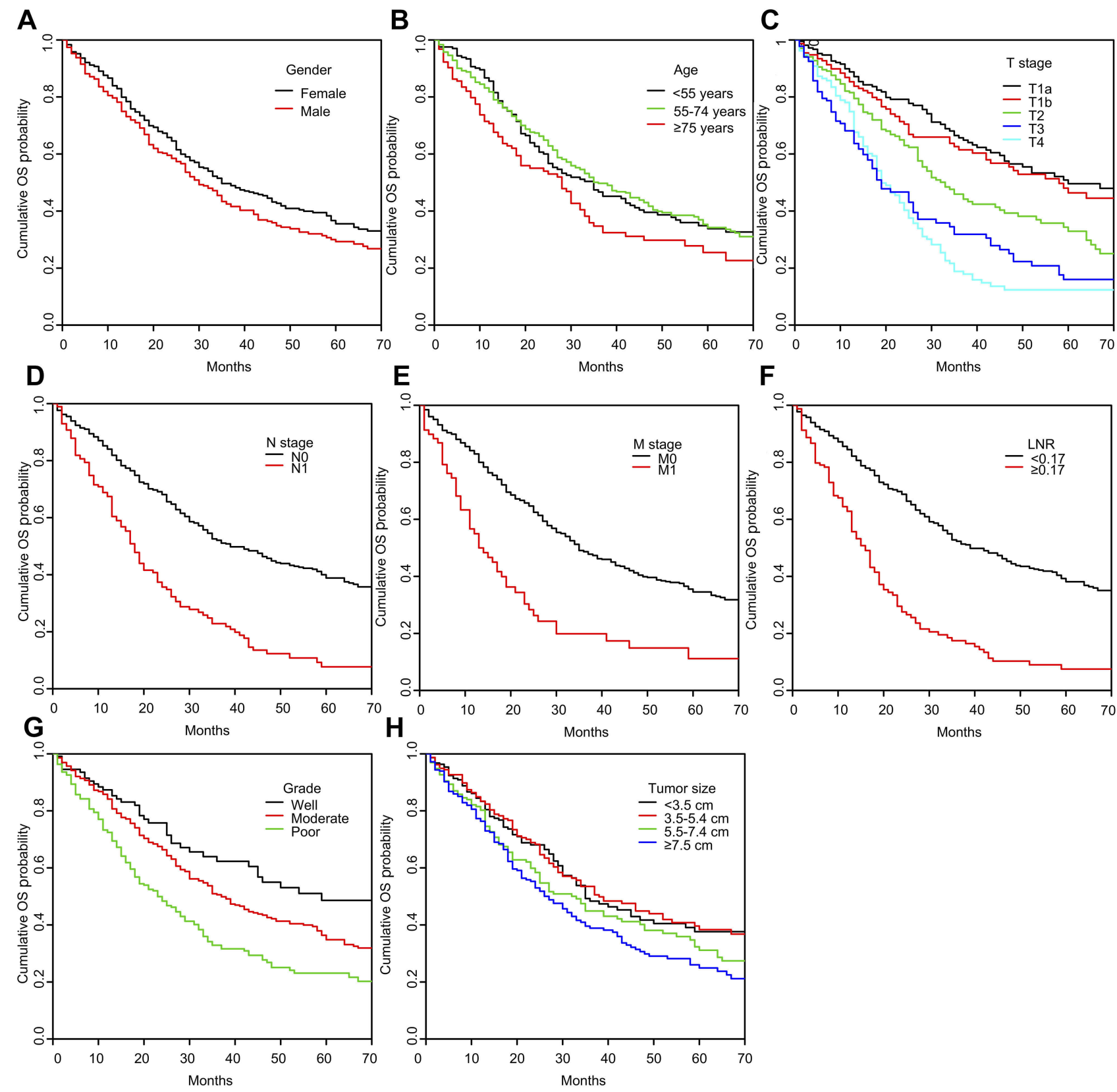

Figure SI Kaplan-Meier cumulative OS curves in patients with ICC after surgery stratified by the clinical characteristics (A) gender; (B) age; (C) T stage; (D) N stage; (E) M stage; (F) LNR; (G) grade; (H) tumor size.

Abbreviations: OS, overall survival; ICC, intrahepatic cholangiocarcinoma; LNR, lymph node ratio. 

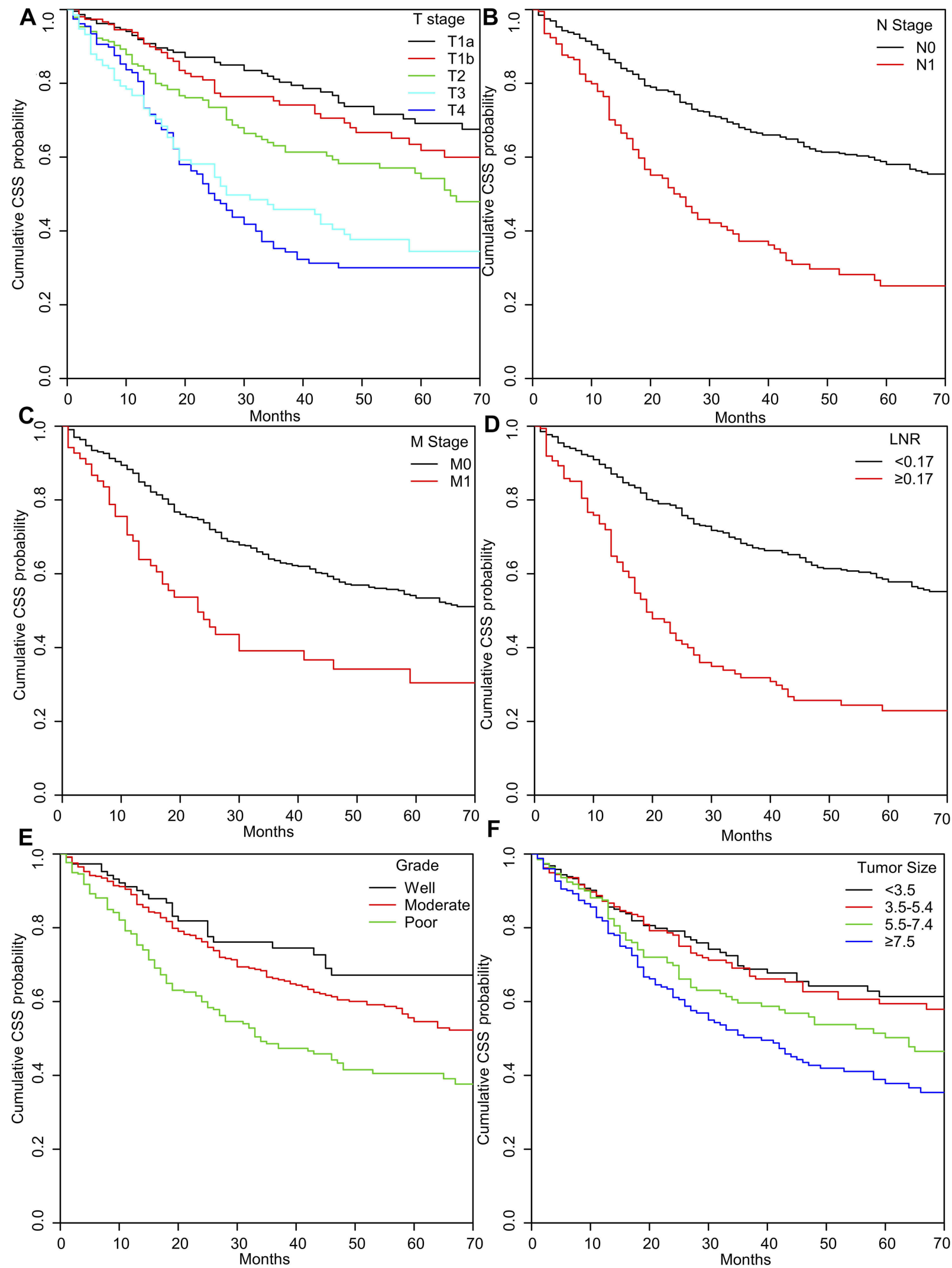

Figure S2 Cumulative CSS in patients with ICC after surgery stratified by the clinical characteristics: (A) T stage; (B) N stage; (C) M stage; (D) LNR; (E) grade; (F) tumor size. Abbreviations: ICC, intrahepatic cholangiocarcinoma; LNR, lymph node ratio; CSS, cancer cancer-specific survival. 

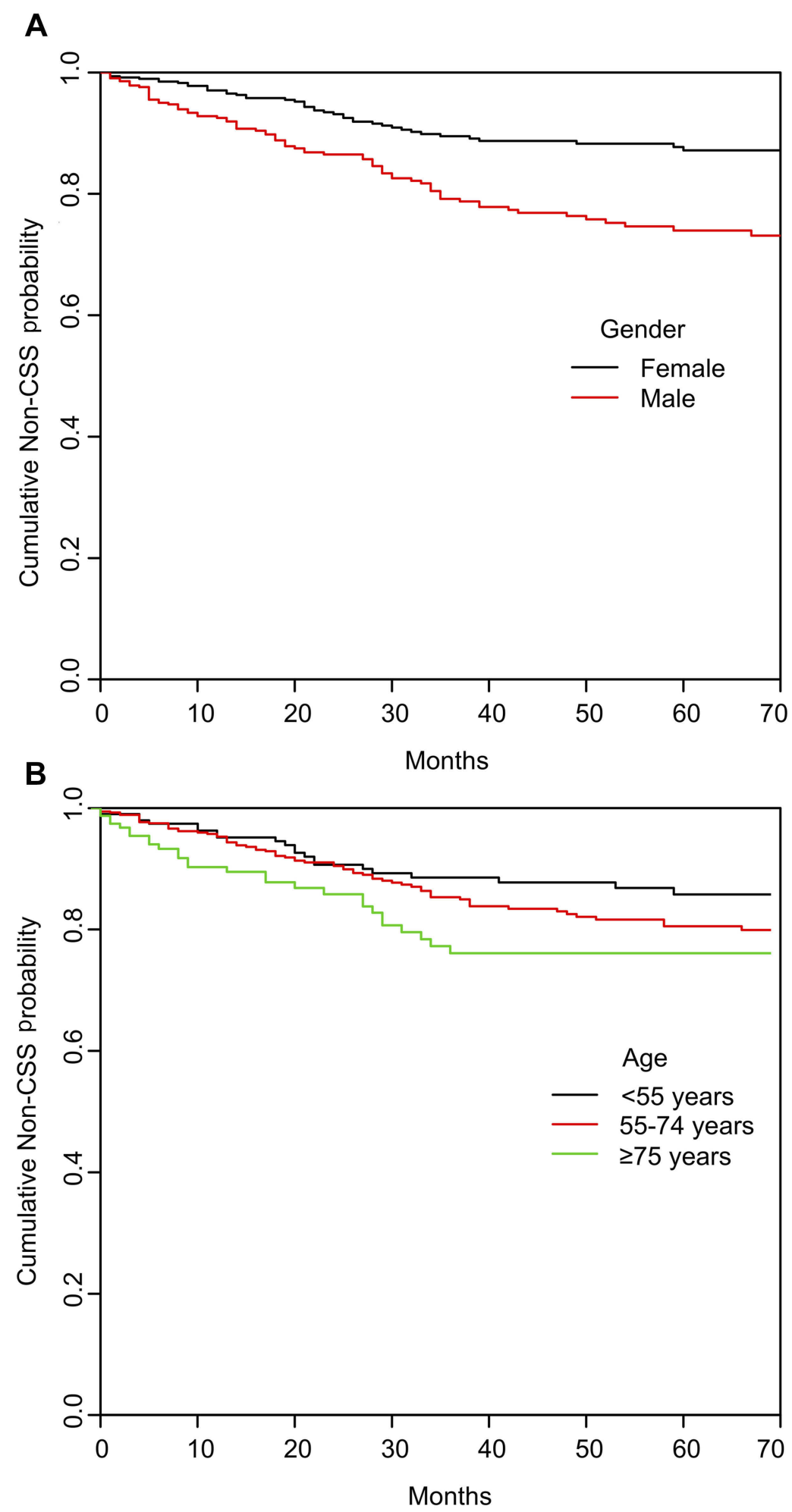

Figure S3 Cumulative non-cancer specific survival in patients with ICC after surgery stratified by the clinical characteristics (A) gender; (B) age. 


\section{Publish your work in this journal}

Cancer Management and Research is an international, peer-reviewed open access journal focusing on cancer research and the optimal use of preventative and integrated treatment interventions to achieve improved outcomes, enhanced survival and quality of life for the cancer patient.

The manuscript management system is completely online and includes a very quick and fair peer-review system, which is all easy to use. Visit http://www.dovepress.com/testimonials.php to read real quotes from published authors. 